\title{
Metallurgical Investigations on Two Sword Blades of 7th and 3rd Century B.C. Found in Central Italy
}

\author{
Walter NICODEMI, Carlo MAPELLI, Roberto VENTURINI and Riccardo RIVA \\ Politecnico di Milano-Dipartimento di Meccanica-Sezione Materiali per Applicazioni Meccaniche, Via La Masa 34,20156
} Milano, Italy. E-mail: walter.nicodemi@polimi.it, carlo.mapelli@polimi.it

(Received on May 26, 2005; accepted on June 24, 2005)

\begin{abstract}
This study aims at casting new light about the knowledge of the metallurgical techniques developed by the Etruscan and the Romans during their political and cultural interactions in Central Italy. The analysis of two weapons found at the Etruscan sites of Vetulonia and Chiusi have pointed out some new information about the production process performed. The optical microscopy analysis has allowed to identify the sequence of the microstructural constituents present in the two ancient weapons. SEM-EDS has permitted to identify the chemical composition of the non metallic inclusion and to estimate the average temperature of the reduction process. The analysis of the metal matrix performed by a coupled argon plasma spectrometer permitted to measure the average chemical compositions of the studied alloys. SEM-EBSD analysis has allowed to identify the crystallographic textures present within the different zones of the sword blades and this has indicated the realization of a forming process that gave interesting mechanical properties to the metal products. The results obtained by the Etruscans artisans were of very high standard quality and their production system had been certainly assimilated by the Romans who found in them a strategic factor to increase their power.
\end{abstract}

KEY WORDS: ancient steelmaking; microstructure; pattern welding; non metallic inclusions; slag; carburization; textures.

\section{Introduction}

The study of the interactions among different cultures can be performed through the systematic and precise study on the archeological findings. They can witness the presence of trade contacts among different peoples but also the contamination among their cultures and their techniques of productions. One of the most interesting phenomenon of assimilation of one people by another is the relation between the Etruscans and the Romans, in which the second ones finally conquered the political predominance but developed not only the exploitation of the Etruscan mines but also went on to perform and to improve the reduction and the forming techniques which would have been fundamental to produce the weapons, a strategic aspect to grant the Roman power. The analysis and the evolution of the techniques could be identified not only by the external aspects i.e. macroscopic shape, but also through the examination of the chemical-physical and crystallographic aspects of the archeological findings, which are strictly related to a well developed and consolidated production process. Particularly, the aspects related to the process of plastic forming need a precise set of the working parameters (i.e. temperature, thickness reduction) to produce repeatable and advantageous crystal orientations within the metal products.

The study performed by Panseri ${ }^{1-3)}$ on some different sword blades produced by the Etruscans and dated in a tem- poral range between the 7 th and the 3 rd century B.C. represents a reference investigation for understanding the skills and the techniques adopted by the metallurgical artisans of the Central Italy in those centuries. The two investigated sword blades were discovered at Vetulonia and at Chianciano, near the famous Etruscan settlement of Chiusi.

The most ancient investigated finding is the bended blade coming from the necropolis of Vetulonia ("Lama Falcata di Vetulonia") which has been dated at the 7th century B.C., while the sword blade found at Chianciano ("Daga di Chiusi") was probably produced during the 3rd century B.C., although precise information about this blade is not available because it had belonged to a private collection until 1915 and then the Italian Republic bought it with the burial stone and the fragments of ceramic vases coming from the same Etruscan tomb site. The ceramic objects and the tomb stone have allowed an almost precise indication of the date of production which can be stated at the 3rd century B.C. The study performed by Panseri is one of the first to realize a systematic description of the techniques applied, from the pattern welding to other not completely understood methods featuring the steel blades ${ }^{4-7)}$ realized by the Etruscans and then by the Romans in the Western world. The conclusions stressed in the former investigations have certainly allowed a first good and interesting description of the main steps and features of the operations followed to produce the sword blades and to strengthen them, including the fascinating process of the pattern welding which joined 


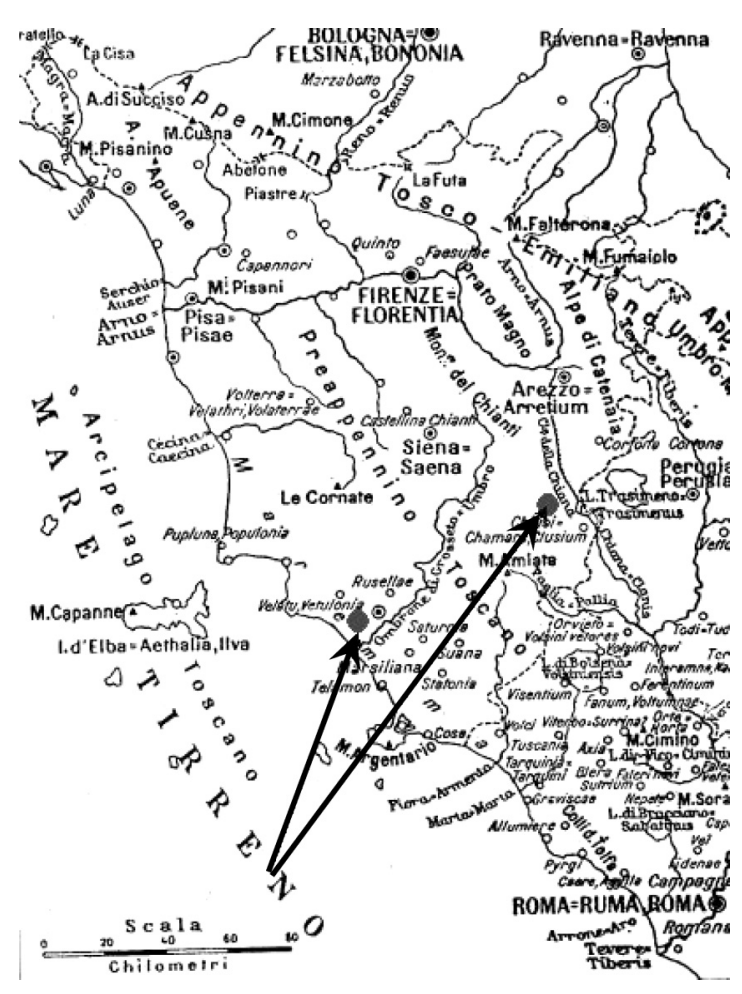

Fig. 1. Representation of the zone in which the analysed swords have been found.

the high and the low carbon steel strips. On the other hand, the modern techniques can allow to reach more precise quantitative information about the metallurgical process through the application of SEM-EDS-EBSD analysis. This last one allows to achieve multiple aims that cannot be obtained by the techniques used during the former investigations performed by Panseri: the identification of the chemical composition of the metal matrix, of the trapped slags and of the non-metallic inclusions embedded in the sword. The quantitative measurements and the thermodynamic elaboration of the compositional data permit to investigate the equilibrium relating slags-non metallic inclusion-steel ${ }^{8)}$ that can provide the possibility of a reliable estimation of the most probable temperature characterizing the reduction process. Moreover, on the basis of this investigation it is possible to formulate new hypothesis about the role of the slags during the welding process. On the other hand, some aspects related to the progressive enrichment of the carbon content found along some blades that had not been produced through this last technique, is not yet clarified, i.e. the EBSD (Electron-Back-Scattered-Diffraction) measurements ${ }^{9)}$ point out the crystallographic structure featuring the different layers of the sword blade identifying the statistical distribution of the orientations assumed by the metal crystals contained in the observed alloys. The preferential orientation of the crystals (textures) and their distribution in the different welded strips and in the different positions of the same strip can cast a new light about the temperature parameters adopted by the plastic deformation process as well as around the mechanical properties featuring the final products which strongly depend on the crystallographic arrangements. In the present study the analysis of the textures has been developed to determine the Orientation Distribution Function (ODF) $)^{10)}$ of the crystals and the tex-

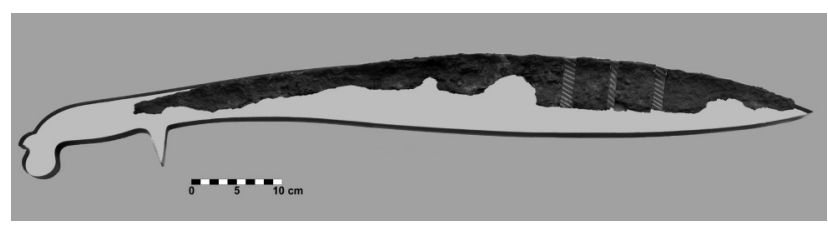

Fig. 2. The sword blade from Vetulonia (7th B.C.) with the reconstruction of the shape supposed by Panseri ("Lama Falcata di Vetulonia"). The analysed samples are contained between the dashed specimens.

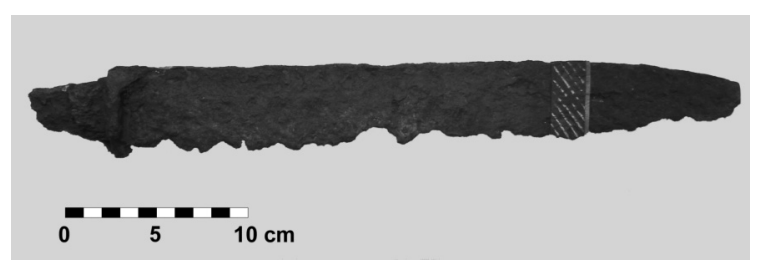

Fig. 3. The sword blade from Chiusi (3rd B.C.) ("La Daga di Chiusi"). The analyzed sample is in the forward adjacent position of the dashed specimen.

ture misorientation. ${ }^{11)}$ This last indicates the average orientation difference along the grain boundaries, which is closely related to the phase transformation and the ricrystallization process induced by the implemented thermal patterns. The articulation of this study has been structured in order to associate the results of the techniques that nowadays are considered traditional with the new investigation techniques, in order to improve the information about the processes used for the construction of the sword blades produced during the Etruscan and the Roman period in Central Italy.

\section{Experimental Procedure}

The sword blade from Vetulonia is $58 \mathrm{~cm}$ long, while the one from Chiusi is $40 \mathrm{~cm}$ long.

On the basis of the state of conservation it is possible to formulate an approximate reconstruction of the original shapes of those weapons. Two specimens were sampled from the blade coming from the necropolis of Vetulonia, which are cut $160 \mathrm{~mm}$ (called SPV1) and $190 \mathrm{~mm}$ (called SPV2) far from the blade side, while the sword blade of Chiusi was cut $125 \mathrm{~mm}$ (SPC) far from its blade side.

The surface which underwent the traditional optical microscope analysis and the SEM (Scanning Electron Microscope) one were prepared in a traditional way. The EBSD (Electron Back Scattered Diffraction) has been performed on surfaces which are polished by the use of colloidal silica which permits to obtain an average roughness of $0.05 \mu \mathrm{m}$.

The SEM observations on the non etched surfaces permit a good detection of the non metallic inclusions and the quantitative measurements of their chemical compositions by EDS (Energy Dispersion Spectroscopy). The precise measurements of the elements contained in the metal matrix have been performed through a spectroscopy analysis by inductively coupled argon plasma spectrometer.

The examination of the structural constituents had been performed by the application of the metallographic etchings. The specimens of the sword blade from Vetulonia 
have been etched by immersion in Nital $1\left(1 \% \mathrm{HNO}_{3}\right.$, $100 \mathrm{ml}$ ethanol) for $5 \mathrm{~s}$, while the ones belonging to the sword blade of Chiusi were etched by immersion in a solution of Picral $\left(2 \mathrm{~g} \mathrm{C}_{6} \mathrm{H}_{3} \mathrm{~N}_{3} \mathrm{O}_{7}\right.$ and $100 \mathrm{ml}$ ethanol) for $7 \mathrm{~s}$ followed by a successive immersion in Nital 1 for $7 \mathrm{~s}$. The etched surfaces had been observed through optical microscopy and SEM observations.

The identification of the development of the adjacent strips has been performed through the use of a optical stereo-microscope on the etched surfaces. This technique can assure the simultaneous focusing of the plane at different steps, although it cannot generally assure significant magnifying.

The crystallographic orientations have been identified through EBSD analysis on the different welded layers and on the different positions of the surface section of the cut specimens. These tests allow to point out the crystallographic textures and analysis of the grain boundaries.

The Vickers micro-hardness has been performed through the use of $50 \mathrm{~g}$ weight applied for $15 \mathrm{~s}$ to evaluate the strength of the detected structural constituents.

\section{Results}

The two sword blades appeared very damaged because of the presence of significant corrosion phenomena which have greatly oxidized and destroyed also the area of the blade section perpendicular to the longitudinal axis.

\subsection{The Sword Blade from Vetulonia}

The observations realized through the stereo-microscope allowed to point out the structure composing the blades which are distinguishable by the sharp chromatic difference featuring the section.

The examinations performed by the stereo-microscope on the whole sections of the specimens of the sword blade from Vetulonia allowed the clear recognition of the welded strips of the steels featured by different carbon contents.

The chemical analysis performed by the spectrometer equipped by inductively argon plasma has revealed that within the regions characterized by the presence of perlite there is an average presence of carbon of $0.15-0.25 \%$ in the SPV1 and SPV2 from the sword blade of Vetulonia, while the strips featured by a nearly complete presence of ferrite are characterized by an average carbon content of $0.05-0.07 \%$. The average silicon content of the sword from Vetulonia is of $0.01 \%$, while the aluminium one is $6 \cdot 10^{-4} \%$ and manganese one is $0.05 \%$.

In the SPV1 and SPV2 the non metallic inclusions are mainly represented by aggregates of two very distinguishable phases, a dark one of $\mathrm{FeO} \cdot \mathrm{SiO}_{2}$ and a clear one rich in $\mathrm{FeO}_{x}$.

The $\mathrm{Al}_{2} \mathrm{O}_{3}$ is present in solution with an average weight concentration of $4.8 \%$. The inclusions present in this sword underline the separation among the strips featured by different structural constituents and these inclusions are characterized by an increase of the $\mathrm{FeO}_{x}$ content which reaches an average value of $91 \%$.

Although the corrosion process has widely compromised the integrity of the lateral zone of the sword through significant oxidation process, the organization of the steel strips
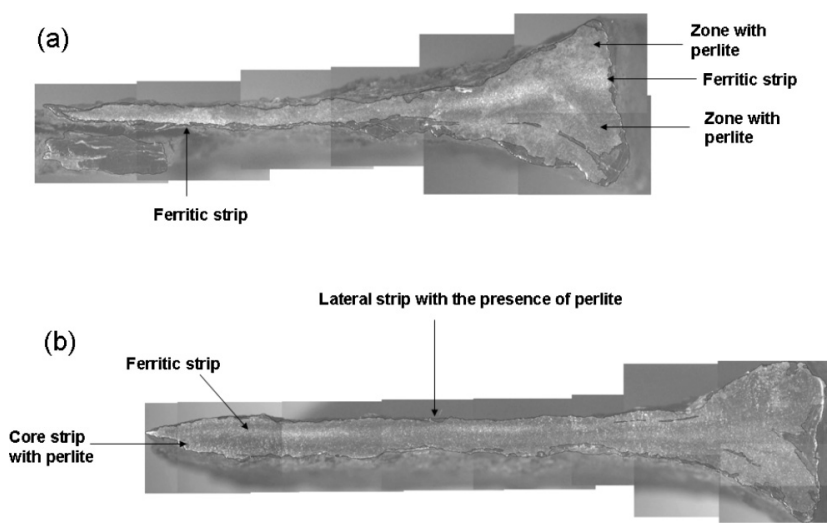

Fig. 4. Different strips evidenced by the chromatic difference (a) in the forward section of SPV1 and (b) in the forward section SPV2.

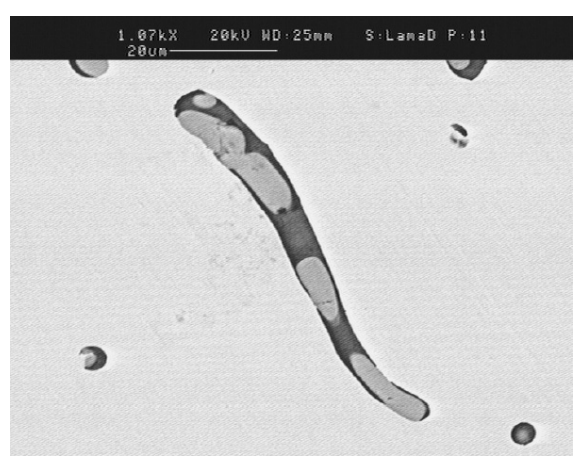

Fig. 5. Example of two phase inclusions composed of $\mathrm{FeO} \cdot \mathrm{SiO}_{2}$ (dark phase) and $\mathrm{FeO}_{x}$ rich aggregates (clear phases).

Table 1. Main elements revealed in non metallic inclusions belonging to the sword from Vetulonia.

\begin{tabular}{|c|c|c|c|c|c|c|c|}
\hline$\%$ wt & $\mathrm{Mg}$ & $\mathrm{Al}$ & $\mathrm{Si}$ & $\mathrm{K}$ & $\mathrm{Ca}$ & $\mathrm{Mn}$ & $\mathrm{Fe}$ \\
\hline 1 clear phase & 0 & 1 & 0 & 0 & 0 & 0 & 99 \\
\hline 1 dark phase & 1 & 8 & 29 & 4 & 5 & 0 & 55 \\
\hline 2 clear phase & 0 & 1 & 0 & 0 & 0 & 0 & 99 \\
\hline 2 dark phase & 1 & 8 & 30 & 4 & 5 & 0 & 52 \\
\hline 3clear phase & 0 & 1 & 0 & 0 & 0 & 0 & 99 \\
\hline 3 dark phase & 1 & 7 & 24 & 3 & 4 & 0 & 61 \\
\hline 4 & 1 & 3 & 24 & 2 & 4 & 3 & 63 \\
\hline 5 & 1 & 3 & 24 & 2 & 4 & 3 & 63 \\
\hline 6 & 2 & 0 & 22 & 0 & 1 & 4 & 71 \\
\hline 7 & 2 & 0 & 24 & 0 & 1 & 3 & 69 \\
\hline 8 & 4 & 11 & 41 & 6 & 5 & 1 & 32 \\
\hline 9 & 3 & 9 & 33 & 3 & 6 & 1 & 45 \\
\hline 10 & 3 & 13 & 41 & 5 & 6 & 1 & 31 \\
\hline 11 & 1 & 5 & 18 & 2 & 1 & 0 & 72 \\
\hline 12 & 0 & 5 & 20 & 2 & 3 & 0 & 69 \\
\hline 13 & 1 & 5 & 21 & 3 & 4 & 1 & 66 \\
\hline 14 & 0 & 0 & 48 & 0 & 0 & 0 & 52 \\
\hline 15 & 0 & 0 & 48 & 0 & 0 & 0 & 52 \\
\hline 16 & 1 & 3 & 17 & 2 & 3 & 2 & 72 \\
\hline 17 & 0 & 0 & 40 & 0 & 0 & 0 & 60 \\
\hline \multicolumn{8}{|c|}{ Oxide on the interface between different strips } \\
\hline 18 & 0 & 0 & 0 & 0 & 0 & 0 & 99 \\
\hline 19 & 0 & 0 & 0 & 0 & 0 & 0 & 100 \\
\hline 20 & 0 & 0 & 1 & 0 & 0 & 0 & 99 \\
\hline 21 & 0 & 0 & 1 & 0 & 0 & 0 & 98 \\
\hline 22 & 1 & 1 & 5 & 0 & 2 & 0 & 91 \\
\hline 23 & 0 & 0 & 0 & 0 & 0 & 0 & 100 \\
\hline 24 & 0 & 0 & 0 & 0 & 0 & 0 & 100 \\
\hline 25 & 1 & 3 & 11 & 1 & 1 & 0 & 83 \\
\hline
\end{tabular}

near the blade in the two swords has pointed out the presence of five welded layers: a central core and two lateral layers with a significant presence of perlite and two ferritic layers embedded among the first ones.

On the other hand, the pattern welding among different strips can be well determined also from the evaluation of the sword back, where in the sword from Vetulonia sharp bands of non metallic inclusions are evident. The structural 


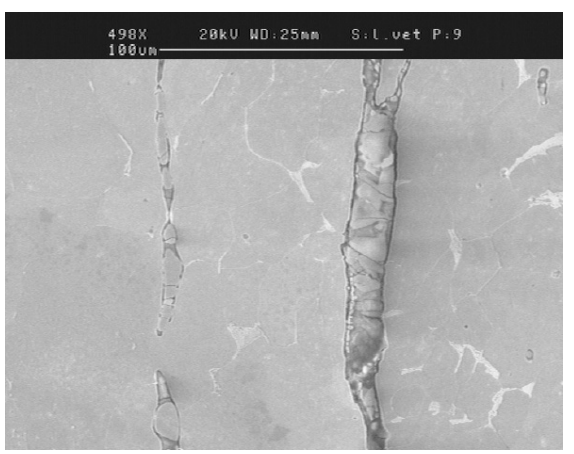

Fig. 6. $\mathrm{FeO}_{x}$ rich inclusions separating the strips of different composition in the sword from Vetulonia.

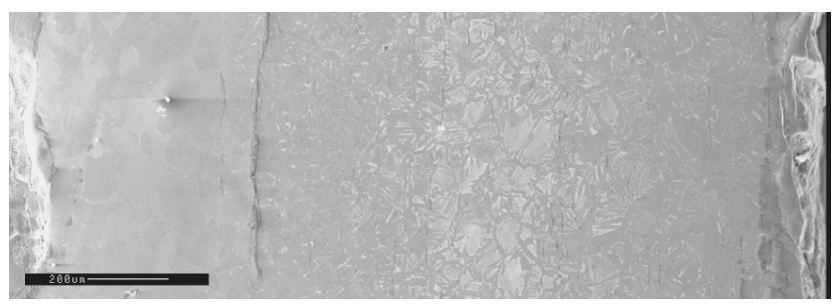

Fig. 7. $\mathrm{FeO}_{x}$ rich inclusions separating the strips of different composition in the sword from Vetulonia.

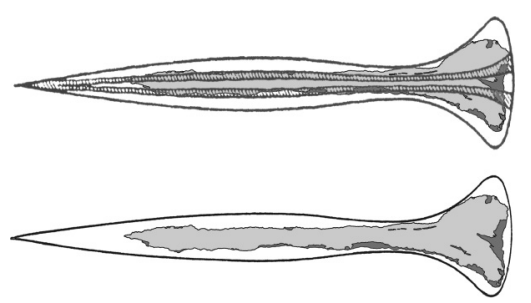

Fig. 8. Reconstruction of the system composed by strips featured by different structural constituents.

constituents revealed by the metallographic etchings show the presence of ferrite and perlite within the section of the blade from Vetulonia.

The measured hardness performed on SPV1 has confirmed the data obtained by Panseri ${ }^{1-3)}$ because at a distance of $19 \mathrm{~mm}$ from the back of the sword the ferritic strip zones of the weapon have revealed an average value of $131 \mathrm{HV}$ while the zones interested by the presence of perlite and acicular ferrite assume values of $217 \mathrm{HV}$. On the contrary, at $42 \mathrm{~mm}$ (nearest the original blade) from the back side of the analysed section the average measured values of the hardness are $209 \mathrm{HV}$.

The EBSD measurements have been discussed on the basis of ODF at $\varphi_{2}=45^{\circ}$ which is the most significant section in the space of the orientations for the body centred cubic lattice. The crystallographic investigation revealed the induction of several crystallographic orientations and misorientations within the different regions of the blade sections.

The indication of texture components is realized by a couple of three indexes, the first one indicating the plane parallel to the section plane and the second one identifying the direction of the lattice perpendicular to the one linking the back of the sword with its blade. The revealed crystallographic textures in the sword from Vetulonia are characterized by components $\{\overline{1} 13\}\langle\overline{3} \overline{3} 2\rangle$ and $\{\overline{1} 11\}\langle 2 \overline{3} 1\rangle$ at the cen-

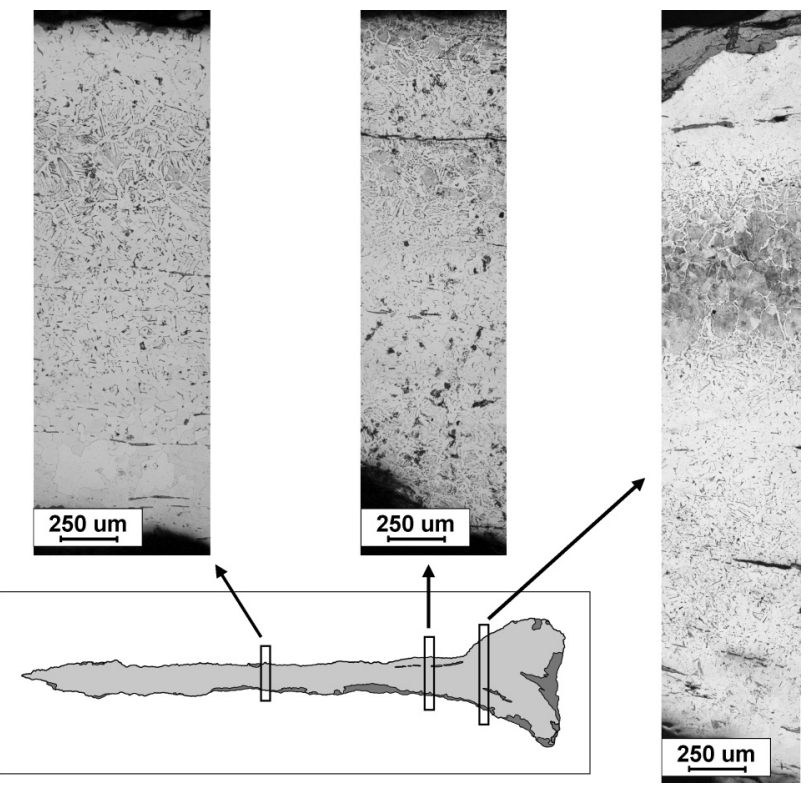

Fig. 9. Evidence of strips featured by different structural constituents in the different zones of the section constituting the sword blade from Vetulonia.

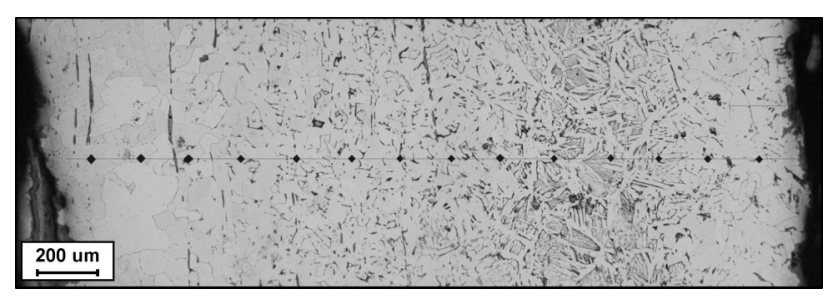

Fig. 10. Micro-hardness measurements performed on the different structural constituents of the sword from Vetulonia.

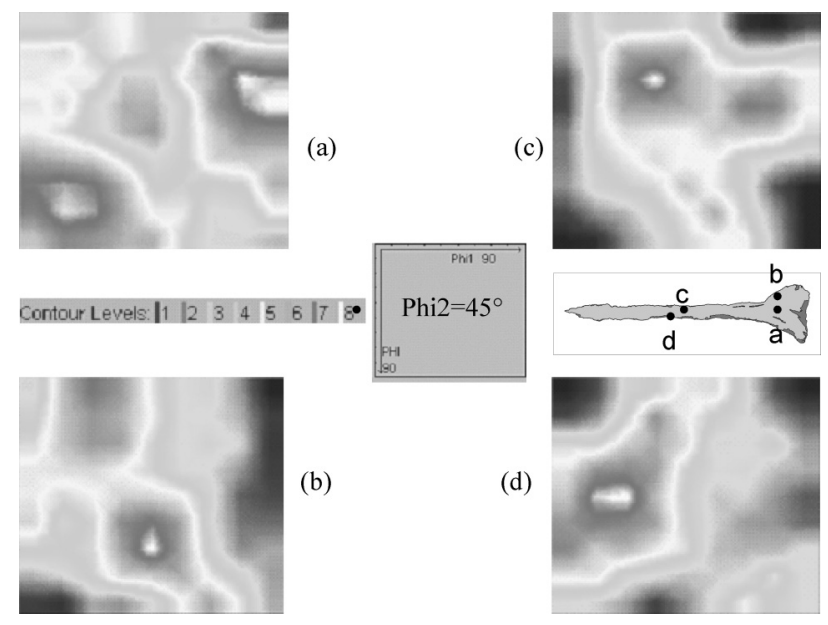

Fig. 11. Revealed ODF of the crystallographic patterns in the sword from Vetulonia. The RD is perpendicular to the axis connecting the back side with the blade region in the sword section.

tre of the back side of the sword blade, and the last component is very sharp also in the lateral region of the back side. The other sharp component revealed at the centre of the section and near the blade are $\{111\}\langle 1 \overline{1} 0\rangle$. The misorientations of the same sword reveal a structure well annealed in the central zone and in the lateral one of the back side, while within the blade there is a significant increase of the 

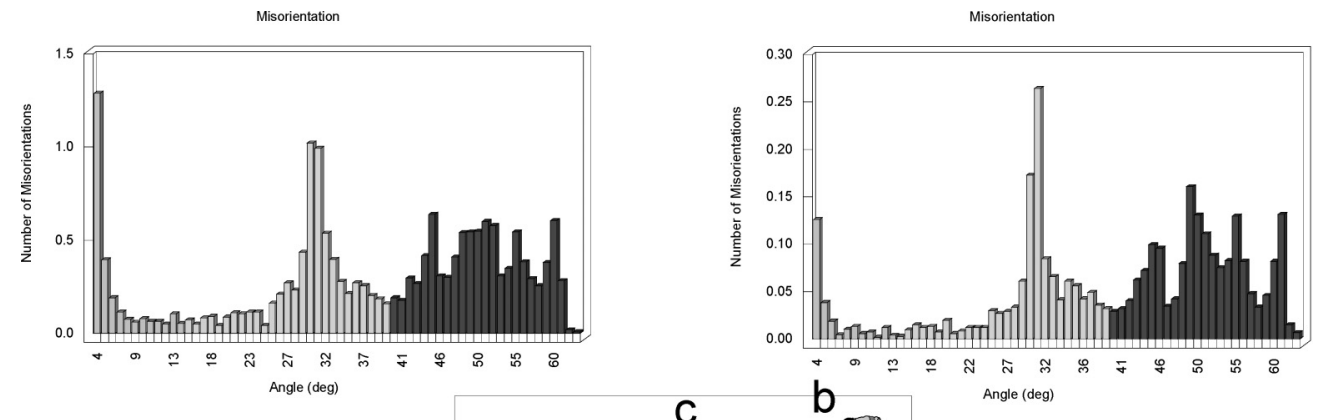

(a)

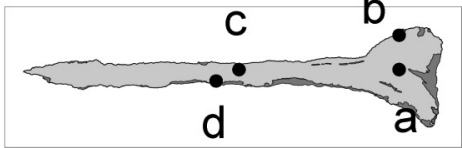

(c)

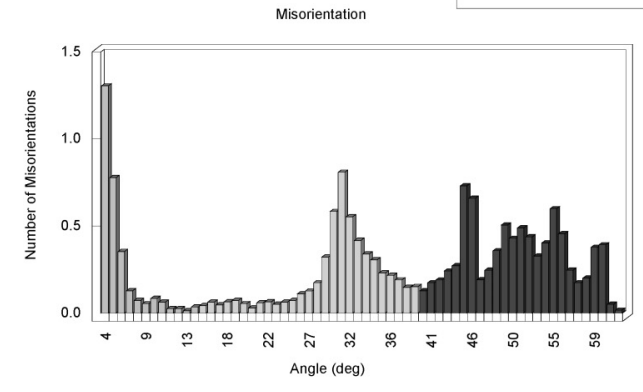

(b)

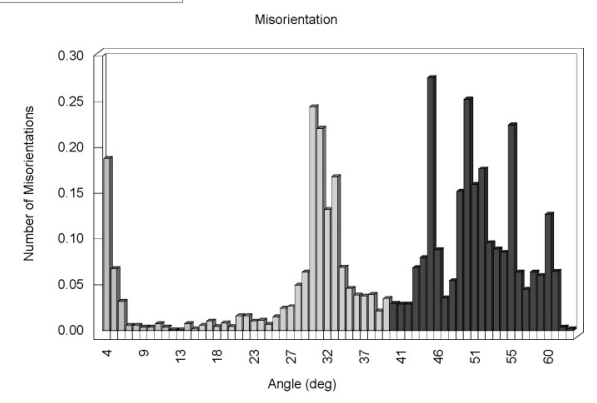

(d)

Fig. 12. Misorientation distribution revealed in the sword from Vetulonia.

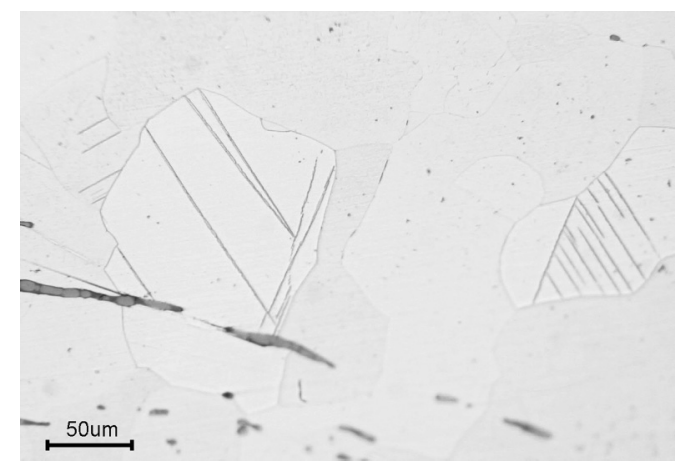

Fig. 13. The Neumann lines found on the back position of the sword from Vetulonia.

boundaries featured by higher relative angles of orientation indicating a structure in which the grain growth process, after the beginning of the ricrystallization, has not gone forward enough to minimize the relative angle among the boundaries as it has happened in the back region of the sword.

The Neumann lines have been pointed out in the ferritic grains belonging to the back of the sword.

The EBSD examination has pointed out that the Neumann lines are a macroscopic evidence of the occurrence of twinning within the ferritic grains which have surely undergone a cold forging operations.

\subsection{The Sword Blade From Chiusi}

The metallographic structure revealed on the etched surface shows a well defined sequence of the structural constituents. The non metallic inclusions embedded in the sword from Chiusi are prevalently of $\mathrm{FeO} \cdot \mathrm{SiO}_{2}$ as in the sword of Vetulonia, but they appear to be saturated by nearly pure $\mathrm{SiO}_{2}$ which indicates the saturation of the inclusion-

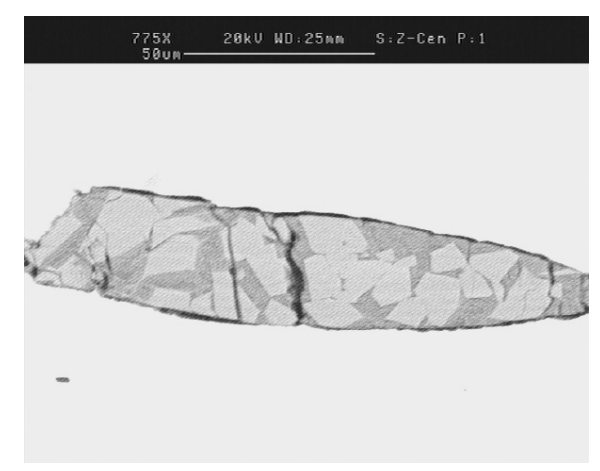

Fig. 14. Example of non metallic inclusions of $\mathrm{FeO} \cdot \mathrm{SiO}_{2}$ included in $\mathrm{SiO}_{2}$ matrix in the sword from Chiusi.

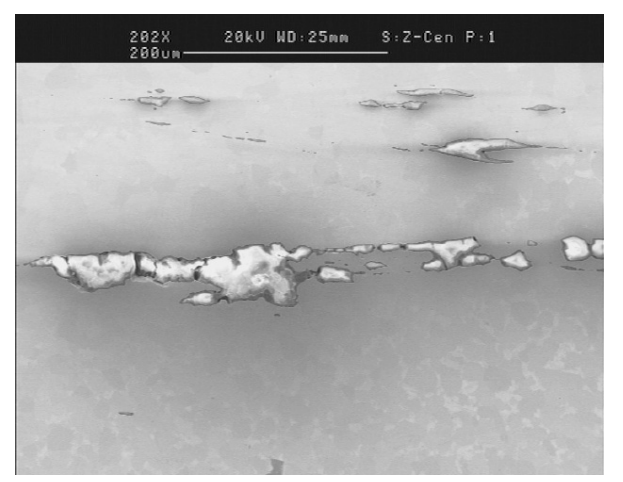

Fig. 15. Example of elongated cluster of non metallic inclusions rich of $\mathrm{FeO} \cdot \mathrm{SiO}_{2}$ in the sword from Chiusi.

al system by $\mathrm{SiO}_{2}$. Less frequent is the presence of nearly pure $\mathrm{SiO}_{2}$.

The frequency of the non-metallic inclusions characterized by a high $\mathrm{FeO}_{x}$ content $(>75 \%)$ is $21 \%$ of the observed population which is less than a half of the one re- 
vealed in the sword from Vetulonia and they are not localized in zones characterized by certain positions, morphological features or in correspondence of the transition from

Table 2. Main elements revealed in the non metallic inclusions belonging to the sword from Chiusi.

\begin{tabular}{|c|c|c|c|c|c|c|c|}
\hline$\%$ wt & $\mathrm{Mg}$ & $\overline{\mathrm{Al}}$ & $\mathrm{Si}$ & $\bar{K}$ & $\mathrm{Ca}$ & $\mathrm{Mn}$ & $\mathrm{Fe}$ \\
\hline 1dark phase & 0 & 2 & 64 & 2 & 1 & 0 & 31 \\
\hline 1clear phase & 0 & 1 & 63 & 1 & 0 & 0 & 33 \\
\hline 2 dark phase & 1 & 3 & 40 & 4 & 1 & 0 & 51 \\
\hline 2 clear phase & 1 & 3 & 43 & 4 & 1 & 0 & 47 \\
\hline 3 & 0 & 0 & 97 & 0 & 0 & 0 & 2 \\
\hline 4 & 1 & 5 & 47 & 2 & 4 & 0 & 41 \\
\hline 5 & 1 & 4 & 43 & 2 & 4 & 0 & 45 \\
\hline 6 & 2 & 4 & 61 & 3 & 3 & 0 & 26 \\
\hline 7 & 2 & 5 & 65 & 3 & 4 & 0 & 22 \\
\hline 8 & 2 & 8 & 50 & 2 & 6 & 1 & 31 \\
\hline 9 & 3 & 7 & 50 & 3 & 4 & 0 & 33 \\
\hline 10 & 0 & 1 & 94 & 0 & 0 & 0 & 4 \\
\hline 11 & 0 & 0 & 98 & 0 & 0 & 0 & 2 \\
\hline 12 & 0 & 1 & 97 & 0 & 0 & 0 & 2 \\
\hline 13 & 1 & 4 & 50 & 2 & 2 & 0 & 41 \\
\hline 14 & 1 & 4 & 46 & 2 & 3 & 0 & 45 \\
\hline 15 & 1 & 5 & 45 & 3 & 3 & 0 & 43 \\
\hline 16 & 1 & 4 & 42 & 2 & 4 & 0 & 47 \\
\hline 17 & 2 & 6 & 46 & 3 & 4 & 0 & 39 \\
\hline 18 & 2 & 6 & 47 & 3 & 4 & 0 & 38 \\
\hline 19 & 0 & 2 & 95 & 0 & 0 & 0 & 3 \\
\hline 20 & 0 & 1 & 97 & 0 & 0 & 0 & 3 \\
\hline 21 & 1 & 0 & 22 & 0 & 0 & 0 & 77 \\
\hline 22 & 1 & 0 & 22 & 0 & 0 & 0 & 77 \\
\hline 23 & 0 & 3 & 34 & 1 & 1 & 0 & 61 \\
\hline 24 & 0 & 5 & 38 & 2 & 3 & 0 & 52 \\
\hline 25 & 1 & 5 & 74 & 2 & 2 & 0 & 16 \\
\hline 26 & 1 & 3 & 44 & 1 & 2 & 0 & 49 \\
\hline 27 & 1 & 4 & 58 & 3 & 3 & 0 & 31 \\
\hline 28 & 2 & 4 & 36 & 1 & 4 & 0 & 53 \\
\hline 29 & 0 & 0 & 0 & 0 & 0 & 0 & 100 \\
\hline 30 & 0 & 0 & 0 & 0 & 0 & 0 & 100 \\
\hline 31 & 1 & 2 & 23 & 1 & 1 & 0 & 72 \\
\hline 32 & 0 & 1 & 98 & 0 & 0 & 0 & 2 \\
\hline 33 & 1 & 3 & 34 & 1 & 2 & 0 & 59 \\
\hline 34 & 1 & 5 & 82 & 2 & 3 & 0 & 6 \\
\hline 35 & 0 & 0 & 0 & 0 & 0 & 0 & 100 \\
\hline 36 & 1 & 3 & 32 & 1 & 2 & 0 & 60 \\
\hline 37 & 1 & 3 & 34 & 2 & 2 & 0 & 57 \\
\hline 38 & 1 & 3 & 33 & 1 & 3 & 0 & 59 \\
\hline 39 & 1 & 3 & 44 & 2 & 3 & 0 & 47 \\
\hline 40 & 1 & 5 & 50 & 3 & 4 & 0 & 38 \\
\hline 41 & 2 & 5 & 59 & 3 & 4 & 0 & 26 \\
\hline 42 & 0 & 2 & 89 & 0 & 0 & 0 & 8 \\
\hline 43 & 1 & 0 & 21 & 0 & 0 & 0 & 78 \\
\hline 44 & 1 & 3 & 40 & 1 & 2 & 0 & 53 \\
\hline 45 & 1 & 2 & 36 & 1 & 2 & 0 & 58 \\
\hline 46 & 1 & 1 & 25 & 1 & 1 & 0 & 72 \\
\hline 47 & 1 & 2 & 30 & 1 & 2 & 0 & 63 \\
\hline 48 & 0 & 1 & 21 & 1 & 1 & 0 & 77 \\
\hline 49 & 0 & 0 & 23 & 0 & 0 & 0 & 77 \\
\hline 50 & 0 & 1 & 15 & 0 & 1 & 0 & 83 \\
\hline 51 & 0 & 0 & 16 & 0 & 0 & 0 & 84 \\
\hline
\end{tabular}

a structural constituent to another one.

The most interesting feature of the observed structural constituents is the increasing content of carbon from the back side of the sword to its blade.

The sequence is very sharp and well defined along the direction linking the back of the sword to the blade: a complete ferritic structure in the back side of the sword, the ferrite grains surrounded by clusters of spheroidal cementite followed by the combination of ferrite grains with the perlitic ones, whose volume fraction becomes progressively higher and in the positions nearest the original blade a strong prevalence of the perlite. This is an evidence of the increasing carbon content along the section of the sword. It is worth noting the presence of the well defined ferritic bands which appear within the perlitic structure near the original blade and are featured by the presence of large ferrite grains.

The carbon content of ferrite varies in the range of $0.05-$ $0.08 \%$ while its average content in the region nearest the blade shows a value of $0.35-0.4 \%$. The silicon content assumes an average value of $0.01 \%$, the aluminium one is $8 \cdot 10^{-4} \%$ and the manganese one is $3 \cdot 10^{-3} \%$.

The measured micro-hardness is consistent with the observed variation of the structural constituents: the completely ferritic grains assume values between $140 \mathrm{HV}$ and $165 \mathrm{HV}$, the zone characterized by the presence of ferrite surrounded by spheroidal cementite is featured by microhardness oscillating between $156 \mathrm{HV}$ and $197 \mathrm{HV}$, the region with the contemporary and nearly equal presence of ferrite and perlite grains assumes values between $211 \mathrm{HV}$ and $228 \mathrm{HV}$ and the nearly complete perlitic structure on the blade region reaches the highest values in the range of

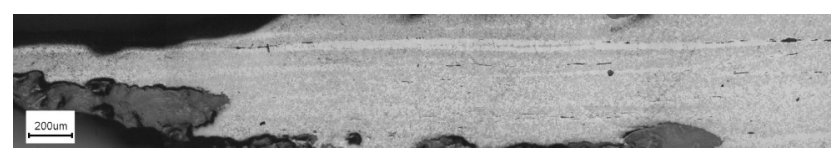

Fig. 17. Examples of banded structure composed by ferrite and perlite in the region nearest the original blade in the sword from Chiusi. a

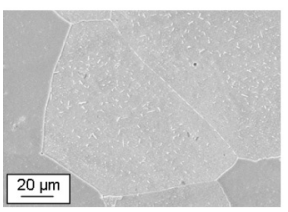

b

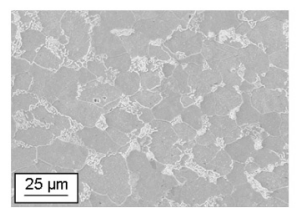

C

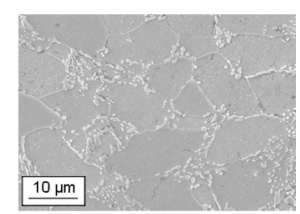

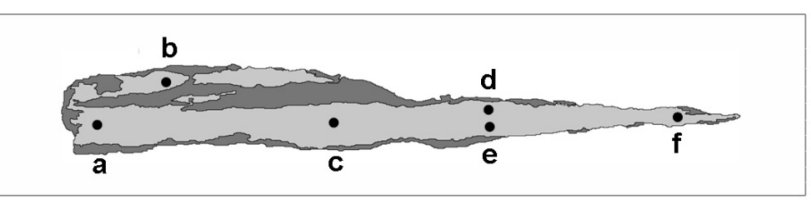

d

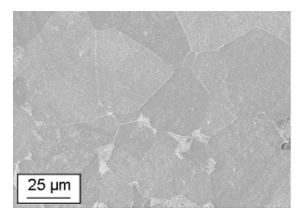

e

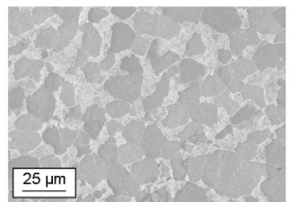

$\mathbf{f}$

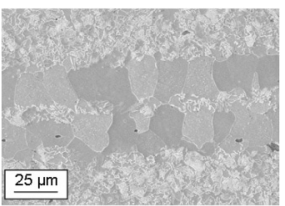

Fig. 16. Sequence of the structural constituents found along the axis connecting the back side of the sword from Chiusi with its blade region. 


\section{$230 \mathrm{HV}$ and $307 \mathrm{HV}$.}

The Neumann lines have been revealed on the ferritic grains of the back region of the sword.

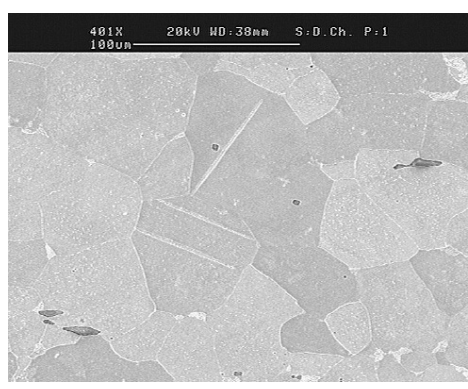

Fig. 18. The Neumann lines in the back of the sword from Chiusi.

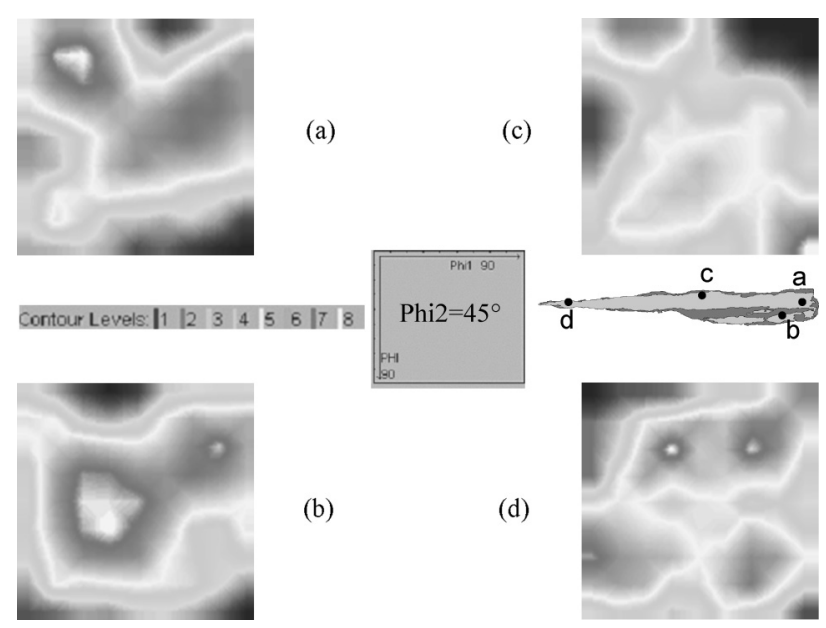

Fig. 19. Revealed ODF of the crystallographic patterns in the sword from Chiusi. The RD is perpendicular to the axis connecting the back side with the blade region in the sword section.
As in the sword from Vetulonia, the EBSD examination has pointed out that the Neumann lines are a macroscopic evidence of the occurrence of twinning within the ferritic grains which have surely undergone a cold forging operations.

The EBSD performed has revealed very sharp $\gamma$-fiber in the region near the blade and a very strong component $\{111\}\langle 1 \overline{2} 1\rangle$, the presence of components $\{110\}\langle 001\rangle$ (Goss), some less intense components featured by $\{110\}\langle 1 \overline{2} 0\rangle$ and the ones containing $\{115\}$ planes.

The misorientation measurements point out a completely recrystallized and annealed structure in the central zone in the back of the sword, but the growth process seems not to have gone on in the regions featured by the finer grain size. The misorientation of the central region of the sword section seems to be characterized by a less annealed structure for the presence of a greater concentration of the higher relative angles among the lattice of the adjacent grains.

\section{Discussion}

Interesting information about the reduction process can be obtained through the correct elaboration of the data related to the equilibrium involving metal-slag-non metallic inclusions. The main oxidation reactions that have to be considered to reach the information for the determination of the average temperature of the reduction process are:

$$
\begin{aligned}
2 \mathrm{Al}+3 \mathrm{O} & \rightarrow \mathrm{Al}_{2} \mathrm{O}_{3} . \\
\mathrm{Si}+2 \mathrm{O} & \rightarrow \mathrm{SiO}_{2} \ldots
\end{aligned}
$$

whose constant of equilibrium can be computed through free energy difference characterizing the chemical reaction:

$$
K_{\mathrm{Me}-\mathrm{MeO}_{x}}=\exp \left(\frac{-\Delta G}{R T}\right)
$$
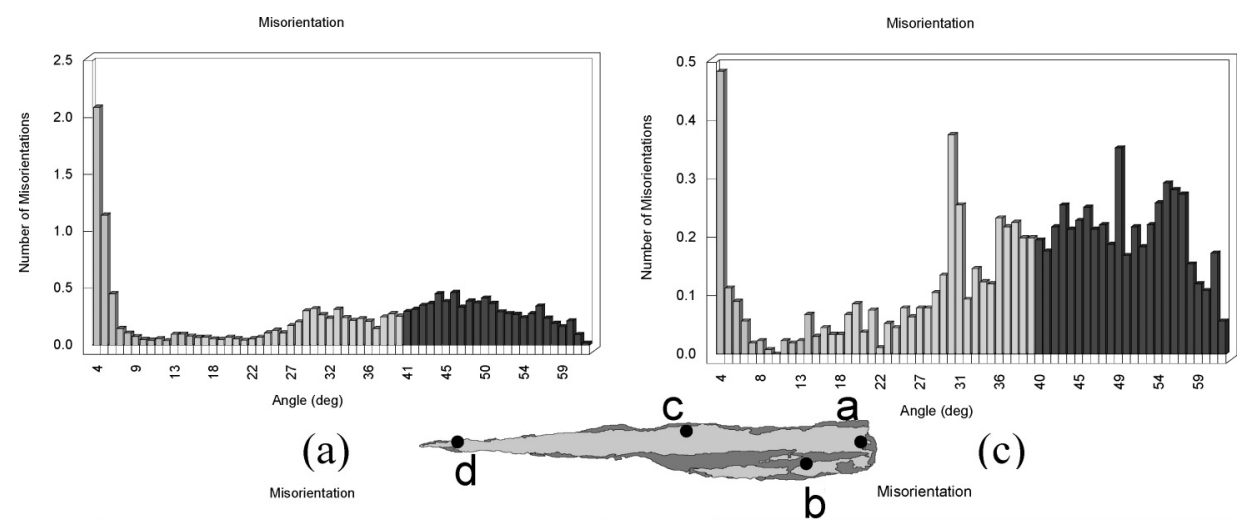

(a)

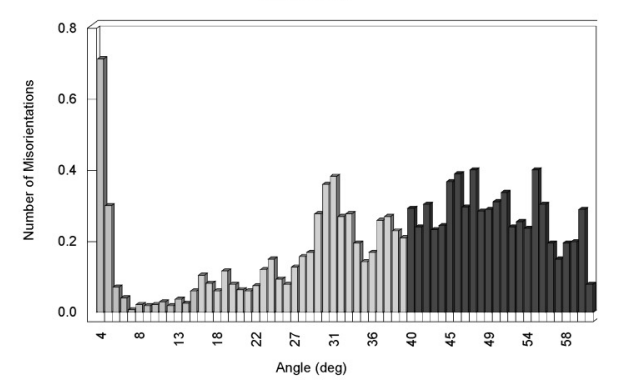

(b)

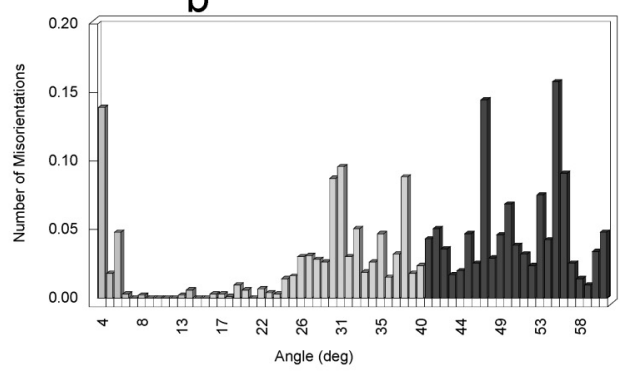

(d)

Fig. 20. Misorientation distribution revealed in the sword from Chiusi. 
where $\Delta G$ is the free energy associated to the reaction, $R$ is the constant of perfect gas, $T$ is the absolute temperature. The variation of the free energy associated with reaction has been computed on the basis of ${ }^{12)}$.

$$
\begin{gathered}
G_{\mathrm{Al}}=-84.5 T+42591 \mathrm{~J} / \mathrm{mol} \mathrm{Al} \ldots \ldots . . \\
G_{\mathrm{Si}}=-58.92 T+30004 \mathrm{~J} / \mathrm{mol} \mathrm{Si} \ldots \ldots . . . \\
G_{\mathrm{O}}=-145.28 T-76028 \mathrm{~J} / \mathrm{mol} \mathrm{O} \ldots \ldots . \\
G_{\mathrm{Al}_{2} \mathrm{O}_{3}}=-235 T-1539859 \mathrm{~J} / \mathrm{mol} \mathrm{Al} \mathrm{O}_{3} . \\
G_{\mathrm{SiO}_{2}}=-134.47 T-848440 \mathrm{~J} / \mathrm{mol} \mathrm{SiO}_{2} .
\end{gathered}
$$

If the chemical composition of the steels and the one of the non metallic inclusions are considered for the sword from Vetulonia, it is possible to impose $a_{\mathrm{SiO}_{2}}=1, a_{\mathrm{Al}_{2} \mathrm{O}_{3}}=$ $0.025, a_{\mathrm{Si}}=9.95 \cdot 10^{-6}, a_{\mathrm{Al}}=1.85 \cdot 10^{-9}$ while for the one from Chiusi $a_{\mathrm{SiO}_{2}}=1, a_{\mathrm{Al}_{2} \mathrm{O}_{3}}=0.01, a_{\mathrm{Si}}=9.88 \cdot 10^{-6}, a_{\mathrm{Al}}=$ $2.46 \cdot 10^{-9}$. The activity of silicon has been computed by the application of an activity coefficient of $3 \cdot 10^{-3}$ and the one of aluminium has been computed through an activity coefficient of $1.5 \cdot 10^{-5} \cdot{ }^{13)}$ The oxygen activity imposed by the two reactions:

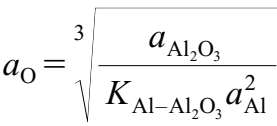

$$
\begin{aligned}
& a_{\mathrm{O}}=\sqrt{\frac{a_{\mathrm{SiO}_{2}}}{K_{\mathrm{Si}_{-} \mathrm{SiO}_{2}} a_{\mathrm{Si}}}}
\end{aligned}
$$

has to assume the same value at the equilibrium. Provided the data of the activities of the other species by the experimental results, the only variable is the temperature that influences the constant of equilibrium of the reaction. Thus, the temperature is modified simultaneously in both equilibrium constants and when expressions provide the same oxygen activity, the correspondent temperature can be assumed as the one at which the reduction process has been performed. For the sword from Vetulonia a temperature of $1163^{\circ} \mathrm{C}$ has been computed, while for the sword from Chiusi a temperature of $1237^{\circ} \mathrm{C}$ has been stated on the basis of this procedure. These computed temperatures do not reach the melting point of $\mathrm{FeO} \cdot \mathrm{SiO}_{2}\left(1470^{\circ} \mathrm{C}\right)$ and the one of $\mathrm{FeO}_{x}$ which is included between $1371^{\circ} \mathrm{C}$ and $1424^{\circ} \mathrm{C}$. On the other hand, the higher thermal state of the bloom from Chiusi could improve the slag extraction because it can increase the softening of the materials. If the dating of the examined swords is reliable, it will be possible to point out that an important aspect of the evolution of the reduction process of iron ores since the 7 th until the $3 \mathrm{rd}$ century B.C. seems to be related to an increase of the average temperature of the reduction process that can be estimated in an increase of about $70 \div 80^{\circ} \mathrm{C}$.

\subsection{The Sword Blade from Vetulonia}

The revealed organization in five different layers represents a clear example of a pattern welding sword which had been damaged by the corrosive process which destroyed by oxidation the outer strips on a large area of the side regions themselves. The modern observations seem to confirm the hypothesis formulated by Panseri ${ }^{1-3)}$ about the original configuration of the different welded layers.

The non metallic inclusions due to the trapping of the reduction slags and the inclusions formed or modified during the welding process can be distinguished by the higher $\mathrm{FeO}_{x}$ content of the non metallic inclusions located on the boundary among the different strips. The shown increase of that oxide is probably due to the further oxidation realized during the performing of the welding process. Thus, this indication offers a good tool to identify the number of the welded strips through the determination of the number of non metallic inclusion series aligned to separate the different strips. It is possible to suppose that the long and aligned series of non metallic inclusions featuring the line of separation along the strips are the residual of the iron oxidized layers formed on the surface just before and during the forging welding operation. The oxidized layers were softened and deformed during the forging operations which realize a friction welding process among the different strips.

The observed textures with a presence of $\{111\}$ planes of the cubic lattice in a position perpendicular to the blade direction should grant an increase of the toughness in the bending deformation often experienced by the swords during their working, although the detrimental presence of components featured by $\{\overline{1} 13\} .{ }^{14)}$ These texture components are certainly caused by a plastic deformation followed by a phase transformation from austenite to ferrite. The favourable components featured by $\{111\}$ planes are formed by high deformation temperature and little austenite grains. ${ }^{15)}$ The fine austenite grains are certainly due to the ricrystallization process which is activated after the application of deformation characterized by specific strain rate. It is possible to evaluate critically the possible thermal state induced during the forging-welding process. The analysis of the reduction process of the sword from Vetulonia has shown that the furnace and the combustion process performed in them can permit to achieve an average reduction temperature just under $1200^{\circ} \mathrm{C}$. During the forging operation the strips interested by the plastic deformation develop the enthalpy through which a large part of the applied work can be dissipated. The thermal increase related to the plastic deformation can be estimated in $120-140^{\circ} \mathrm{C}$, but among the surface of the different strips further heat can be developed by the friction which implies an increase of about $100-120^{\circ} \mathrm{C}$. The sum of those different contributes can permit the localized solid joining of the steels through a process analogous to the modern friction welding process. This seems to be proved also by the fact that the misorientation measurements indicate that the core did not undergo a complete growth of the recrystallized grains as the highest value of the relative angle characterizing the distribution of the misorientation witnesses. On the contrary, the outer layers seem to have experienced a more complete annealing process. This can be probably due to the fact that the heat development had mostly interested the layers which are most strained by the contacts with the working tools. These layers are certainly the ones belonging to the outer strips and the surface between the ones near the surface separating the strips. So, the misorientation of the core strips presents a higher value of the relative angles among the adjacent grain crystals than the ones shown by the outer ones. 


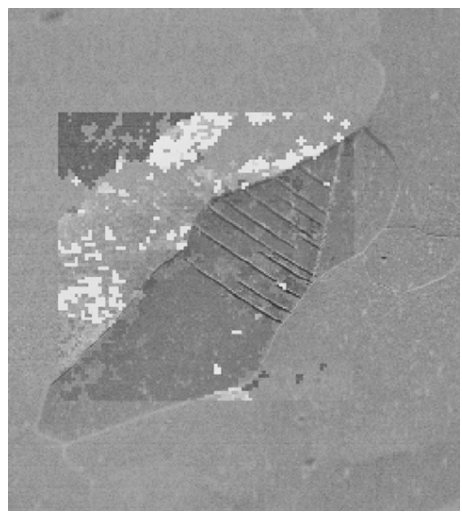

Fig. 21. The twinnings revealed by EBSD analysis in correspondence of the Neumann lines. The different colours imposed by the measurements device on the Neumann lines point out the different orientations of the adjacent zones.

This analysis involving the grain boundaries shows the particular misorientation of the core which is certainly due to a different thermal distribution within the adjacent layers. The core did not undergo a ricrystallization and annealing process. The strengthening operation has been increased in the sword blade from Chiusi through a rapid cooling which produces acicular ferrite. Although the ancient artisans did not know this crystallographic aspects, they had certainly found the thermal pattern realized on these friction welded structure very suitable and reliable for such a type of weapons. Actually, the fracture cracks find a great obstacle in the boundary characterized by a relative angle larger than $15^{\circ}$, because they meet a crystal orientation too different from the one in which they are propagating. ${ }^{16)}$ Thus, the reliability of the core of the metal system formed through pattern welding after repeated cycles of stress application appears to be certainly more granted.

The presence of the Neumann lines is the macroscopic evidence of the occurrence of plastic deformation realized by twinnings and not by sliding.

The twinnings in the ferrite can form only after the a violente plastic deformation and so they indicate a clear role of this operation in the hardening of the ferrite low carbon strips as a final strengthening operation.

\subsection{The Sword Blade from Chiusi}

The observations point out that this blade has not been produced by pattern welding because a more reliable explanation can be found in the forging of a steel produced by a bloom featured by a varying carbon content. Another possibility related to this carbon gradient can be the performing of a carburising process which has been formerly proved in other findings ${ }^{1)}$ which permitted the possible reconstruction of this process. The presence of the observed sharp ferrite band within the perlitic structure is due to the elongation of a little volume of ferrite during the plastic deformation. The starting reducing bloom has a gradient of the carbon content which has been exploited to modulate the micro-structure and the related mechanical properties. The absence of revealed patterns of the welding is indicated also by the richer $\mathrm{FeO}_{x}$ non metallic inclusions and this corroborates the hypothesis that this sword has not been realized by the pattern welding technique. The textures induced in the sword show a high presence of component with $\{111\}$ and $\{110\}$ plane contained in the plane of the analysed section. These components can increase toughness during the bending deformation that occurs when the blade is in its working condition. The misorientation measurements show that at the centre of the blade section and in region of finer grain size near the back side, the statistical distribution of the relative angles tends to be concentrated on angles greater than $15^{\circ}$.

The particular misorientation of the finer grain size at the centre of the blade section is certainly due to a different thermal distribution realized by the thermo-mechanical cycles imposed by the plastic deformation. On the basis of the evaluation formulated for the sword from Vetulonia it is possible to state that the outer layers undergone a thermomechanical cycle which is around $100 \div 150^{\circ} \mathrm{C}$ higher than the core ones.

As pointed out for the sword from Vetulonia, the presence of the Neumann lines is the macroscopic evidence of the occurrence of plastic deformation realized by twinnings and not by sliding. The twinnings in the ferrite can form only after the cold plastic deformation and so they indicate a clear role of this operation in the hardening of the ferrite low carbon strips as a final strengthening operation.

\section{Conclusion}

It is surprising that although the ancient Etruscan artisans do not have a deep knowledge of the basic principle related to the physical and mechanical metallurgy they succeed in realizing very interesting products as the two examined swords. Particularly, the most ancient sword from Vetulonia represent a typical example of the pattern welding techniques which has a strong analogy with the friction welding process, while the samples taken from the sword found at Chiusi seem to have been realized starting from a reduced bloom characterized by gradient in the carbon content. It cannot be excluded that this carbon gradient has been realized through a carburising process which can cast a new bright light on the experience developed by the Etruscans and then by Romans in the thermochemical treatments.

The present study has permitted to:

(1) identify the production process used to realize the two analysed swords: the one from Vetulonia dated to the 7 th century B.C. has been produced by the welding pattern process through the welding of strips characterized by different carbon content and so by different structural constituents, while the sword from Chiusi dated to the 3rd century B.C. seems to be realized through the forging of a single bloom, or portion of bloom, interested by a carbon gradient along the direction connecting the back and the region of the blade (this gradient could be realized also through the implementation of a carburising process);

(2) the thermodynamic computation about the equilibrium involving the system composed by metal-non metallic inclusions-slag has allowed to estimate the average temperature reduction process which has been stated at $1163^{\circ} \mathrm{C}$ for the sword from Vetulonia and at $1237^{\circ} \mathrm{C}$ for the one from Chiusi;

(3) the chemical composition of the non metallic inclu- 
sions composed by the materials of the trapped slags has an average chemical composition corresponding to $\mathrm{FeO} \cdot \mathrm{SiO}_{2}$, on the contrary the ones distributed along the separation lines among the different strips belonging to the sword from Vetulonia are characterized by a higher $\mathrm{FeO}_{x}$ content of the other ones, so the presence of this type of inclusions can be used to distinguish the different strips and their separation boundaries can be recognized on the basis of the chemical characterization of the non metallic inclusions;

(4) the forging operations performed for realizing the two swords had covered a fundamental role not only to realize the desired shape, but also to realize the desired thermal situation which is conditioned also by the heat developed by the plastic deformation process which can produce an increase of the temperature that can be situated in a range of $100-150^{\circ} \mathrm{C}$ and interesting prevalently the outer sword layers which underwent the more intense plastic deformation than the inner ones;

(5) in the pattern welding process revealed in the sword from Vetulonia the friction between the different layers that takes place during the hot forging can imply a further thermal increase which should promote the process of formation of the solid joining of the alloys on the strip boundaries. The joining had been realized through the welding of five steel strips: one at the core and two lateral outer ones of ferrite, which are separated by two intermediate layers enriched by carbon to form perlite and acicular ferrite after the cooling;

(6) the textures induced by the applied thermo-mechanical cycle seem to grant a greater toughness of the sword blade during the bending operations and the high presence of favourable texture components featured by a significant presence of $\{111\}$ planes parallel to the observed metallographic sections. The textures observed are certainly derived from austenite-ferrite transformation and they can be caused by deformation of austenitic grains at high temperature and after a ricrystallization inducing a fine grain size;

(7) the distribution of misorientation shows the concentration towards the higher relative angles in the core layer and near the blade, so the growth process cannot fully develop in the core layers. This can be regarded as another evidence that the heat developed by the forging operations and concentrated in the outer layers covered a fundamental role in conditioning the microstructural evolution and the growth process of the recrystallized grains;

(8) the presence of Neumann lines within the ferrite contained in the back of the sword is the evidence of a plastic deformation which took place through twinnings in place of sliding. This event can be caused only by an impulsive cold forging process and the presence of Neumann lines indicates that the cold deformation is the final finishing step of the production of the swords.
The examined ancient findings point out the great skill developed in the Etruscan areas. Although some of these areas (i.e. Vetulonia) have been deserted for the presence of malaria, it is very interesting that the developed knowledge have been transmitted to the Roman people and certainly this interaction has covered a great role in the formation and building of the Roman military power on Mediterranean Sea which has been based also on the efficiency and functionality of the produced weapons.

\section{Acknowledgement}

The authors desire to thank very much the FONDAZIONE NOVARA SVILUPPO in Novara which has stored the investigated archeological findings until today and has permitted the new observations realized at Politecnico di Milano to improve the knowledge and the application of the modern techniques for the updating of the study performed on these ancient objects. Moreover, the authors desire to thank very much also Mr. Piero Pellin for his precious help in the development of the present research.

\section{REFERENCES}

1) C. Panseri, C. Carino and M. Leoni: Metallographichal Investigation about Some Steel Etruscan Sword Blades, Istituto Sperimentale Metalli Leggeri, Milano, (1957), 1.

2) C. Panseri: Metallographical Examination on a 7th Century B.C. Bended Sword Blade Found in Vetulonia's Necropolis, Istituto Sperimentale Metalli Leggeri, Internal Report, $\mathrm{n}^{\circ}$ 561257/6459, Novara, (1956).

3) C. Panseri: Examination of a 3rd Century B.C. Etruscan Sword Blade Found in Chiusi, Istituto Sperimentale Metalli Leggeri, Internal Report, $\mathrm{n}^{\circ}$ 570140/6515, Novara, (1957).

4) R. F. Tylecote: A History of Metallurgy, Maney for the Institute of Materials, London, (1992), 66.

5) A. Giumlia Mair and R. Maddin: The Iron Civilization, ed. by W. Nicodemi, Edizioni Olivares, Milano, (2004), 113.

6) F. Bressan: Ancient Metallurgy between Oriental Alps and Pannonian Plain, Vol. 8, ed. by A. Giumlia Mair, Quaderni dell'Associazione Nazionale per Aquileia, Aquileia, (2000), 207.

7) C. Panseri: Gladius, 4 (1963), 5.

8) W. Nicodemi and C. Mapelli: La Revue de Metallurgie, 12 (2004), 1.

9) F. J. Humphreys and M. Hatherly: Recrystallization and Related Annealing Phenomena, Elsevier, Oxford, (2004), 546.

10) F. J. Humphreys and M. Hatherly: Recrystallization and Related Annealing Phenomena, Elsevier, Oxford, (2004), 527.

11) W. B. Hutchinson and M. Hatherly: An Introduction to Texture in Metals, The Institution of Metallurgist, Monograph 5, The Institute of Metals, London, (1979).

12) I. Barin, O. Knacke and O. Kubashewski: Thermochemical Properties of Inorganic Substances, Springer Verlag, Berlin, (1973).

13) B. Sundman, G. K. Sigworth and J. F. Elliot: ThermoCalc Users Guide, IRSID and Royal Institute of Technology, Stockholm, (1999).

14) J. R. Hirsh, W. B. Hutchinson and K. Lücke: Textures Microstruct, 14 (1991), 691.

15) R. K. Ray, M. P. Butron-Guillen, J. J. Jonas and G. E. Ruddle: ISIJ Int., 32 (1992), No. 2, 203.

16) D. Bhattacharjee and C. L. Davis: Scr. Mater, 47 (2002), 825. 